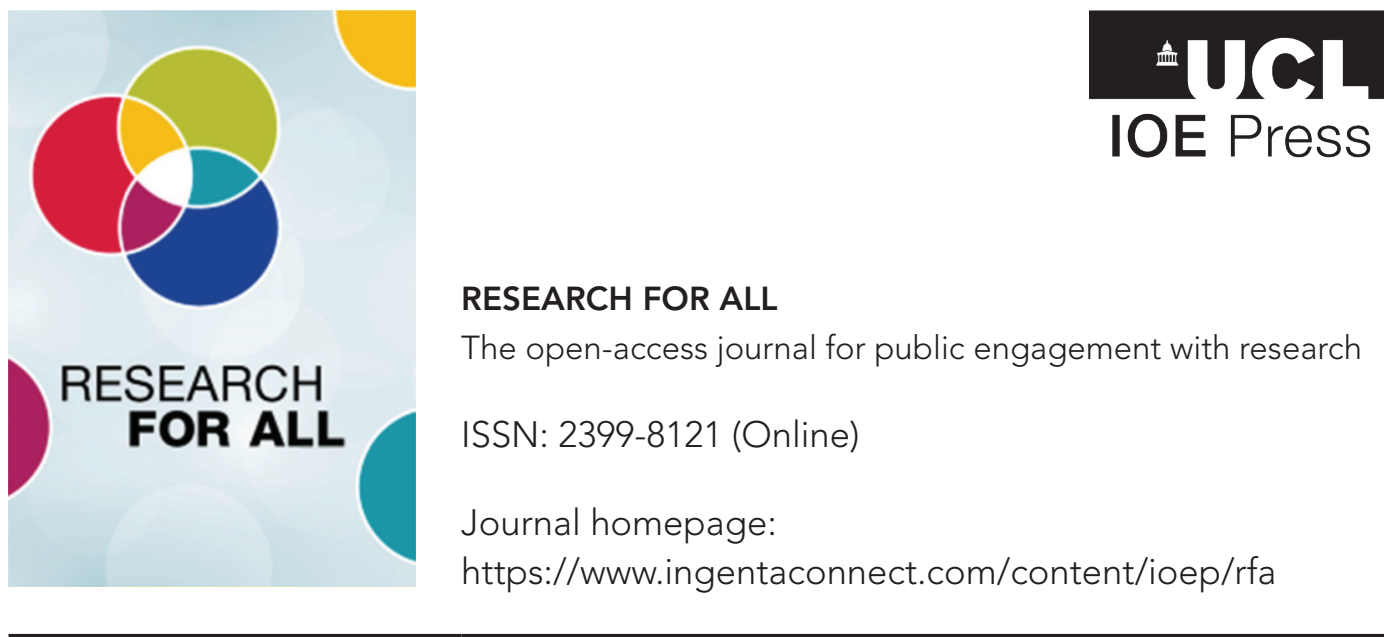

\title{
Improving the quantitative research skills of Welsh Baccalaureate teachers through university engagement
}

\author{
Charlotte Brookfield (iD and Samuel Parker (D)
}

\section{How to cite this article}

Brookfield, C. and Parker, S. (2020) 'Improving the quantitative research skills of Welsh Baccalaureate teachers through university engagement'. Research for All, 4 (1): 102-16. DOI https://doi.org/10.18546/RFA.04.1.08

Submission date: 17 December 2018

Acceptance date: 10 September 2019

Publication date: 1 February 2020

\section{Peer review}

This article has been peer reviewed through the journal's standard double-blind peer review, where both the reviewers and authors are anonymized during review.

\section{Copyright}

(C) Copyright 2020 Brookfield and Parker. This is an Open Access article distributed under the terms of the Creative Commons Attribution Licence (CC BY) 4.0 https://creativecommons.org/licenses/by/4.0/, which permits unrestricted use, distribution and reproduction in any medium, provided the original author and source are credited.

\section{Open access}

Research for All is a peer-reviewed open-access journal. 


\title{
Improving the quantitative research skills of Welsh Baccalaureate teachers through university engagement
}

\author{
Charlotte Brookfield* and Samuel Parker - Cardiff University, UK
}

\begin{abstract}
In 2015, the redesigned Welsh Baccalaureate Qualification (WBQ) was launched and, for the first time, students undertaking the qualification were required to complete the Skills Challenge Certificate (SCC). Consisting of four components - the Individual Project, the Enterprise and Employability Challenge, the Global Citizenship Challenge and the Community Challenge - the SCC aims to enable learners to develop skills needed for education, employment and life. The Individual Project requires students to undertake a research project that includes analysing data utilizing quantitative data analysis skills. This paper identifies the teaching of such quantitative skills as a difficulty for some teachers involved in the delivery of the qualification, drawing on recent engagement work between Cardiff University and schools and colleges in South Wales. It argues that universities have an opportunity to engage with schools, teachers and school students in the delivery of quantitative research skills that can be beneficial for both schools and universities.
\end{abstract}

Keywords: Welsh Baccalaureate, Skills Challenge Certificate, individual investigation, quantitative research, number, Q-Step

\section{Key messages}

- The reconfigured Welsh Baccalaureate Qualification introduced in 2015 requires students to undertake an Individual Project utilizing quantitative research and data analysis skills.

- Engagement work by Cardiff University with teachers delivering the qualification has revealed that many teachers lack the confidence and skills to deliver quantitative research and data analysis teaching to their students undertaking the Welsh Baccalaureate Qualification.

- Engagement work by universities in quantitative research methods can help to address this gap and ensure that students undertaking the Welsh Baccalaureate Qualification have the skills needed to be successful.

\section{Introduction}

Academics are increasingly being required to undertake engagement and outreach activities in addition to the traditional teaching and research functions of universities (Johnson et al., 2019). Much of this can be seen as contributing towards what many 
universities now describe as their 'civic mission'. Bartel et al. (2003: 90) have suggested that historically such engagement and outreach activities were not seen as contributing to the core mission of the university, and were devalued in comparison to teaching and research. However, they argue that outreach and engagement with schools can not only address social and environmental issues, but also enhance teaching and research efforts.

Much of the existing literature focuses on outreach and engagement with schools from the perspective of the student (for example, Michels and Eijkelhof, 2018; Tansey and Gallo, 2018). Such studies therefore tend to focus on the benefits to school students in terms of knowledge and skills development resulting from university outreach, or to the universities themselves in terms of future student recruitment or good public relations. While some research has found that teachers positively value university outreach programmes for their students (Shaw et al., 2010), what is less widely discussed in the literature is university outreach work with teachers themselves, and the potential benefits that this can bring. This paper seeks to address this gap in the current literature through presenting a case study of how one project at Cardiff University has sought to engage with teachers of the Welsh Baccalaureate Qualification (WBQ) as part of its 'civic mission'. As such, it will be of interest to academics who are considering developing their own outreach programmes with schoolteachers, both in Wales for teachers of the WBO and also more widely across the UK, where teachers may be required to deliver the Extended Project Qualification (EPQ).

This paper begins with an overview of the introduction and development of the WBO since 2003. Here, we argue that the introduction of the Individual Project component of the qualification, which requires students to demonstrate, and therefore teachers to deliver, higher-level numeracy and quantitative research skills, provides an opportunity for universities in Wales to engage with teachers as part of their university's 'civic mission'. Following this, we outline a case study of recent outreach activities delivered by the Cardiff Q-Step Centre, focusing particularly on the 2018 teacher conference. Analyses of the attendance information and feedback from the event are presented, and we argue that this points to important opportunities for universities to engage with teachers as part of their 'civic mission'.

\section{What is the Welsh Baccalaureate Qualification?}

The Welsh Baccalaureate Qualification (WBO) is a qualification for 14- to 19-yearold students in Wales. Following funding from the Welsh Government, it was initially piloted in 18 schools and further education (FE) colleges across Wales in 2003. By the end of 2005, 31 schools and colleges were piloting the qualification before it was rolled out across Wales in September 2007, following broad support for the qualification from schools and colleges (Greatbatch et al., 2006). Yhnell et al. (2016) report that the qualification was offered in over 240 centres in September 2011 and highlighted that over 70,000 students would take the qualification in 2013. The WBO was initially available for students to undertake at three levels - foundation, intermediate and advanced - and combined 'general and/or vocational education (through existing qualifications) with the development of key skills that are intended to equip young people with the skills they need after leaving school' (National Assembly for Wales Research Service, 2015: 1). Elements of the WBO initially included: Essential Skills Wales and Key Skills; Wales, Europe and the World; Work-related Education; Personal and Social Education; and the Individual Investigation. 
In the Review of Qualifications for 14 to 19-year-olds in Wales (Welsh Government, 2012), employability skills, the broad nature of the qualification and the accommodation of academic and vocational pathways within the qualification were noted as particular strengths (Yhnell et al., 2016). However, the report also recommended that the WBO should be revised to make it more rigorous, include grading at advanced level (previously students only received a pass or fail result), and to ensure more effective engagement between education providers and employers.

A revised Welsh Baccalaureate Qualification was introduced across Wales in September 2015. In addition to including grading of the advanced qualification, the revised WBO introduced a new element, the Skills Challenge Certificate (SCC). The SCC comprises four elements that students must complete in order to achieve the qualification: Community Challenge, Global Citizenship Challenge, Enterprise and Employability Challenge and the Individual Project. The Welsh Joint Education Committee (WJEC), which awards the WBQ, states that 'The primary aim is to enable learners to develop and demonstrate an understanding of and proficiency in essential and employability skills: Communication, Numeracy, Digital Literacy, Planning and Organisation, Creativity and Innovation, Critical Thinking and Problem Solving, and Personal Effectiveness' (WJEC, 2019). In particular, the Individual Project requires learners to develop high levels of independent study and research skills, thus preparing them for higher education (HE) or employment.

In a review of the implementation of the new qualification in September 2015, Qualifications Wales (2016) highlights the training offered to teachers delivering the new WBO as a particular issue. Drawing on feedback from teachers, they note that the focus of training appeared to be on the design of the qualification, while there was insufficient advice on delivering the new Skills Challenge Certificate. To gain top marks in the Individual Project, students must not only demonstrate independent research skills, but also higher-level numeracy and quantitative data analysis skills.

More recently, the National Assembly for Wales (Children, Young People and Education Committee, 2019) carried out an inquiry into the status of the WBO. Speaking to a wide range of stakeholders, including students, teachers, universities and ministers, the report shows that the WBO has a number of benefits for the students who study it, particularly in terms of the skills developed for future study or life. However, the inquiry also concluded that the delivery of the qualification and the way it is publicized has had a negative impact on its actual and perceived value. The report highlights, in particular, the need for there to be specialist WBO teachers and specific timetabled classes for the WBQ, so that the WBQ is delivered by teachers fully trained in the qualification and that lessons are not only timetabled at the end of term when teachers have more availability.

This paper seeks to address the following question: 'How can universities support teachers and schools to deliver the quantitative research methods skills required as part of the Individual Project component of the Skills Challenge Certificate?' We suggest that such skills are often a concern to teach for those delivering the WBQ, and that universities therefore have a key role to play in engaging with schools delivering the WBQ. In the next section, we discuss research that has been conducted with teachers of the WBO and then provide an overview of engagement work that the Cardiff Q-Step Centre (part of Cardiff University's School of Social Sciences) has undertaken with schools and colleges in South Wales. 


\section{Teaching the Welsh Baccalaureate Qualification}

Estyn (2018), the education and training inspectorate for Wales, states that the teaching and level of enthusiasm for the WBO remain variable between schools and colleges in Wales. The 2018 report concludes that students are not adequately developing their numeracy skills as part of the WBO. Specifically, the report states that students make 'perfunctory use of statistical information' and that only a minority 'exhibit a suitable grasp of numeracy' (ibid.: 14). Estyn (2018) link this deficiency to a lack of experience and expertise among teachers involved with delivery of the qualification in Welsh schools and colleges. The report suggests that timetabling, as opposed to skill level and knowledge, dictates who teaches the qualification, and therefore there are instances where teachers lack familiarity and confidence with the numerical skills they need to deliver the qualification effectively. This problem is exacerbated by the lack of access that teachers have to networks of good practice. Similarly, in her thesis, Golding (2013) provides a description of a personal tutor in a school in the South Wales valleys who was somewhat apprehensive to support the delivery of the WBQ, having had no previous teaching or research experience. These findings underscore the role that higher education institutions can play in bringing together and supporting teachers in learning how to carry out research effectively.

Grigg (2016) asked teachers to rate the effectiveness of different education policies implemented by the Welsh Government. Almost 40 per cent of respondents (66) rated the WBQ as a 'poor' or 'very poor' initiative, in comparison to 30 per cent (57) who believed it was 'good' or 'very good'. The remaining teachers were neutral over the introduction and implementation of the WBQ. Grigg (2016) argues that the WBO is just one of a number of initiatives that have been introduced to the Welsh education system in recent years, and that, increasingly, teachers are feeling that there are too many new initiatives to deliver on.

Despite this, increasingly, the WBO advanced level qualification is being recognized outside schools and colleges (Gunning and Raffe, 2011). All Welsh universities now recognize the qualification as part of their admissions process and, gradually, higher education providers outside Wales are recognizing the value of the WBO. Furthermore, employers see the qualification as an effective mechanism for preparing young people for the workplace. Therefore, it is important to ensure that training opportunities are available for all Welsh Baccalaureate teachers, regardless of the main subject that they teach or their educational background, to ensure that they are able to give their students the best opportunities and prospects. In particular, the need to equip students with numerical skills is becoming ever more important in our digitalized society, where numerical data are increasingly routinely collected (Savage and Burrows, 2007; Savage, 2009; Savage and Burrows, 2009). In the section that follows, we introduce the Cardiff Q-Step Centre, created in order to improve the numerical and quantitative research skills of students in the UK; and, following this, we outline how the centre has been undertaking outreach activities with Welsh Baccalaureate teachers.

\section{The Cardiff Q-Step Centre}

In 2011, in response to calls to improve the numerical skills of the UK (British Academy, 2012), and specifically the quantitative research methods skills of social science students, the Nuffield Foundation, the Economic and Social Research Council and the Higher Education Funding Council for England launched a f19.5 million project, 
the Q-Step programme. This initiative is working in collaboration with 15 universities across the UK, including Cardiff University's School of Social Sciences. The Cardiff Q-Step Centre of Excellence in Quantitative Methods Teaching and Learning has two core aims. First, through extensive module and curriculum redesign, it is committed to increasing the research methods training provision for social science undergraduate students at Cardiff University. Second, it aims to work with schools and colleges in the local community to improve students' ability and confidence to utilize numerical data in order to undertake research projects. This second aim is in line with the Nuffield Foundation's original commitment to embedding quantitative methods of teaching and learning throughout the educational life course of students (Nuffield Foundation, n.d.). It is deemed that such intensive and sustained engagement with research methods is needed in order to bring about necessary change in students' confidence and ability to engage with a variety of approaches and methods. In turn, it is hoped that this will go some way towards upskilling the UK labour force. Indeed, Universities UK (2015) reports that at present, there is a shortage of skilled graduates capable of managing large quantitative data sets or producing quantitative analysis.

\section{Cardiff University Welsh Baccalaureate outreach activities}

The Welsh Baccalaureate Qualification's Skills Challenge Certificate has provided a vehicle for the Cardiff Q-Step Centre to implement its ambition to enthuse young people about the potential of quantitative research. For instance, in the academic years 2016/17 and 2017/18 the centre hosted students completing both the national and advanced level of the qualification for skills workshops. This included sessions on the key stages of the research process, sampling strategies, survey design and data analysis. Additional workshops have been delivered in collaboration with the university's widening participation team, which have focused on how numerical data can enhance our understanding of global social inequalities. Alongside this, the centre has delivered continuing professional development sessions on research skills for teachers. Perhaps the most significant evidence of the centre's commitment to this goal is the development of a Level 3 qualification in social analytics. This qualification equips students with techniques to utilize numerical data in order to investigate social issues ranging from health, to crime and to education. The qualification has been delivered for four years, and most recently has been delivered alongside Welsh Baccalaureate Skills Challenge Certificate lessons in a local college. A further FE provider in South Wales is also piloting the qualification as a prerequisite course for A-level students undertaking the Extended Project Qualification.

However, it is not only students with whom the Q-Step Centre has sought to engage. Since the introduction of the revised Welsh Baccalaureate Qualification, the Cardiff Q-Step Centre has hosted an annual teacher conference on the qualification. The aim of the conference is to give teachers the confidence to deliver research methods teaching in their classroom, and therefore to allow their students to undertake focused, feasible and interesting research. This paper evaluates data collected at the 2018 conference to demonstrate the role that universities can play in equipping teachers with the tools to deliver quantitative research methods teaching effectively.

As part of the 2018 Skills Challenge Certificate Conference, there were two quantitative research methods workshops. The first workshop was concerned with understanding different levels of data and being able to effectively write survey questions to obtain all levels of data. The second quantitative workshop introduced delegates to cross tabulations and the chi-square statistic. These workshops sat alongside other 
sessions on creating interview schedules and analysing interview transcripts. There were also talks from Cardiff University's Schools Health Research Network and Open Access Team on the resources they have freely available to teachers delivering the SCC. As such, the event aimed not only to provide training to teachers, but also to provide them with ideas for teaching in their own classrooms.

Talking specifically about UK higher education, Johnson et al. (2019) argue that, with the introduction of policies including the removal of the cap on student numbers and increased student fees, institutions across the UK are under increased pressure to undertake civic duties and engage with external agencies. However, despite this increased scrutiny, Johnson et al. (2019) suggest that there remains very little motivation among some academics to undertake such work, with outreach activities often being sidelined as administrative work. Indeed, Johnson et al. (2019) found that often academics do not have such work recognized in their workload model, and even in instances where such work was accounted for, the allocation was often insufficient. This means that time devoted to outreach and engagement work often impinges on time set aside for other research and scholarly activities, which can be considered by some institutions as more imperative in the promotion process. Talking specifically about engaging with schools, Johnson et al. (2019) highlight the added constraint of negotiating a suitable time to undertake engagement work with the tightening of curriculum space. The authors suggest that administrative support and/or student interns can be extremely valuable for academics who wish to carry out such work. For the case study shared in this paper, a paid postgraduate student and a member of administrative staff within the university assisted extensively with the planning, delivery and evaluation of the event.

\section{Skills Challenge Certificate Conference 2018}

\section{A case study of engagement}

The 2018 Welsh Baccalaureate Skills Challenge Certificate Teachers Conference took place on Friday 21 September 2018. This paper draws on both registration and evaluation data for the event to report a case study of school engagement. Scholarly activities that engage directly with teachers are often under-reported, and the findings from such work are rarely disseminated (Johnson et al., 2019). Therefore, while this paper is based on findings from a small number of teachers and, indeed, is not generalizable to the whole population, it begins to give us an insight into how HE providers can engage with teachers, and into some of the challenges that HE providers may face when delivering school engagement activities.

The data for this paper were analysed both quantitatively and qualitatively. Due to the small number of participants and the non-probability sampling approach employed, the quantitative findings merely provide a snapshot of some of the challenges that teachers face in delivering research skills teaching. Further to this, the small number of respondents has restricted the extent to which this quantitative data can be analysed and, as such, the paper presents descriptive statistics only. For Likert scale questions, the data have been treated as ordinal and the median response (middle response) has been reported. The median score can be calculated when you have logically ordered categorical data. As a measure of central tendency, it is considered to be less affected by extreme values or skewed data. The qualitative data presented in this paper are used to complement and illustrate the ideas that began to emerge from the analysis 
of the quantitative data. The qualitative data were analysed thematically, and salient themes that emerged from the data are reported as part of this case study.

In total, 62 delegates registered to attend the event, with 51 delegates actually attending the event. There was some attrition in response rate in the registration data; therefore, not all the totals reported in this paper sum to 62. The cognitive burden involved in completing surveys can have a direct impact on response rate. In order to maintain response rates and to avoid attrition, it is recommended that researchers minimize the length of their survey tools and avoid using too many open-response questions (Crawford et al., 2001). This, along with a well-formatted survey and an incentive, can encourage participation. For the present research, the registration data were downloaded from Eventbrite. While questions can be posed in the registration forms created through Eventbrite, it is first and foremost a mode for promoting and registering for events and not a survey software tool. This means that the question format types are limited, and therefore, in some instances, this may have been somewhat off-putting for delegates. In addition to this, the Eventbrite registration form contained a number of mandatory questions including name, dietary and access needs. These questions, along with a few others, were essential to ensure that the event ran smoothly and was health and safety compliant. As a result, these questions were presented first, and were followed by additional questions. It is possible that some participants did not wish to invest the additional cognitive burden to complete the non-mandatory, later sections of the registration form. Finally, it is worth noting that the Welsh Language Standards (Welsh Government, 2018) stipulate that all public events must be advertised bilingually, with the Welsh version appearing first. This meant that non-Welsh-speaking teachers who registered for the event had to scroll and click through all registration questions in Welsh before reaching the English ones. This may have caused some frustration among some delegates and, again, may have increased the attrition rate.

As well as the mandatory questions in the registration form, delegates were also asked about the subject(s) they taught, the key issues or concerns they had with teaching the Skills Challenge Certificate, and for details of what they hoped to achieve from attending the conference.

At the end of the conference, delegates were asked to complete a short evaluation form. In order to encourage participation, time was set aside during the closing address for the teachers to do this. The evaluation form aimed to measure how relevant teachers found each of the workshops. It asked delegates to score each of the workshops they attended on a 5-point Likert scale from 'Very relevant' to 'Not at all relevant'. Delegates were encouraged to report on the most and least successful aspects of the conference.

\section{Sample demographics}

While the sample is non-probabilistic, many of the schools and colleges in the region were represented at the conference and representatives from the two regional consortiums attended the event. The Central South Consortium and the Educational Achievement Service for South East Wales work to develop and implement change in schools in order to raise educational standards. The consortiums cover the following areas of South Wales: Bridgend, Cardiff, Merthyr Tydfil, Rhondda Cynon Taf, Vale of Glamorgan, Blaenau Gwent, Caerphilly, Monmouthshire, Newport and Torfaen. 
As shown in Table 1, the majority (77 per cent) of the delegates registered were teachers. The 47 teachers who attended the conference came from 35 different schools and colleges from across South Wales.

Table 1: Delegate type

\begin{tabular}{lcc} 
Delegate type & Frequency & Valid percentage (\%) \\
\hline Teacher & 47 & 77.0 \\
Other & 14 & 23.0 \\
\hline
\end{tabular}

Table 2 shows the number of years of experience the delegates had delivering the qualification. The greatest proportion (38.6 per cent) had taught the qualification for one to three years. However, a sizeable percentage (33.3 per cent) had been delivering the qualification for four to eight years, thus demonstrating the importance of engaging with experienced as well as newly qualified teachers.

Table 2: Years' experience teaching the Welsh Baccalaureate Qualification

\begin{tabular}{lcc}
\hline Years' experience teaching WBO & Frequency & Valid percentage (\%) \\
\hline Less than 1 year & 4 & 7.0 \\
1 to 3 years & 22 & 38.6 \\
4 to 8 years & 19 & 33.3 \\
Over 8 years & 6 & 10.8 \\
Not applicable & 6 & 10.8 \\
\hline
\end{tabular}

Table 3: Main subject taught

\begin{tabular}{lcc}
\hline Main subject & Frequency & $\begin{array}{c}\text { Valid } \\
\text { percentage (\%) }\end{array}$ \\
\hline Animal management & 1 & 1.9 \\
Art & 2 & 3.8 \\
Business and economics & 4 & 7.7 \\
Criminology & 1 & 1.9 \\
French & 1 & 1.9 \\
Geography & 1 & 1.9 \\
Information technology & 3 & 5.8 \\
Media studies & 1 & 1.9 \\
Photography & 2 & 3.8 \\
Public services & 1 & 1.9 \\
Religious education & 2 & 3.8 \\
Science (including physics, chemistry and biology) & 3 & 5.8 \\
WBO & 28 & 53.8 \\
Welsh & 2 & 3.8 \\
\hline
\end{tabular}


Most of the delegates (53.8 per cent) who registered reported that the main subject they taught was the Welsh Baccalaureate Qualification. However, Table 3 shows the range of disciplines that teachers delivering the qualification came from, including business and economics (7.7 per cent), art (3.8 per cent) and religious studies (3.8 per cent). From this evidence, there appears to be very few science, technology, engineering and mathematics (STEM) teachers delivering the qualification. There were no maths teachers registered, and only three science teachers. This reflects the fact that school timetabling, as opposed to expertise, often dictates who delivers the qualification (Estyn, 2018). Maths, science, English and Welsh are compulsory subjects for all Welsh students until the age of 16; therefore, these teachers are likely to have much more demanding workloads and are less likely to be delivering the SCC. As a result of fewer STEM teachers delivering the qualification, those teaching the SCC may be less confident in numeracy and quantitative analysis. This underscores the importance of university outreach in supporting these teachers.

The following section will present data on the challenges that teachers delivering research skills teaching face, and will discuss the role that university outreach can play in addressing these challenges.

\section{Registration data}

When registering, delegates were asked to list any key issues or concerns that they had about delivering the SCC. Table 4 provides a summary of these data. For this question, some participants listed more than one concern; therefore, each response does not necessarily represent a unique delegate. The concern listed with the greatest prevalence was numeracy or quantitative skills (35.7 per cent). This concern was listed much more frequently than other issues, such as engagement ( 14.3 per cent), enterprise (7.1 per cent), and level descriptors that indicate the intended outcomes of learning (7.1 per cent). Equally, when asked about what they aimed to gain from attending the event, 7 per cent of those who responded made reference to research skills and data analysis (see Table 5).

Table 4: Registration data - key issues or concerns with teaching the Skills Challenge Certificate

\begin{tabular}{lcc}
\hline $\begin{array}{l}\text { Do you have any key issues or } \\
\text { concerns with teaching the SCC? }\end{array}$ & Frequency & $\begin{array}{c}\text { Valid } \\
\text { percentage (\%) }\end{array}$ \\
\hline Numeracy and quantitative analysis & 5 & 35.7 \\
Research skills & 1 & 7.1 \\
Engagement & 2 & 14.3 \\
Enterprise & 1 & 7.1 \\
Community & 1 & 7.1 \\
Importance to students & 1 & 7.1 \\
Level descriptors & 1 & 7.1 \\
New ideas for teaching and learning & 1 & 7.1 \\
Amount of content & 1 & 7.1 \\
\hline
\end{tabular}


Table 5: Registration data - aim of attending the event

\begin{tabular}{lcc}
$\begin{array}{l}\text { What do you aim to get from attending the } \\
\text { event? }\end{array}$ & Frequency & $\begin{array}{c}\text { Valid } \\
\text { percentage (\%) }\end{array}$ \\
\hline Teaching ideas & 20 & 35.1 \\
Knowledge and information about qualification & 17 & 29.8 \\
Professional development & 4 & 7.0 \\
Networking opportunities & 11 & 19.2 \\
Research skills (including data analysis) & 4 & 7.0 \\
Improved marks for Individual Investigation & 1 & 1.7 \\
\hline
\end{tabular}

Furthermore, participants who registered gave information on how they believed Cardiff University could best support them with delivery of the WBO SCC. Again, many delegates listed more than one response, and therefore each response does not necessarily represent a different delegate. Comments included 'the advanced numeracy element for the project', 'handling data' and 'the use of numeracy for the individual project' (see Table 6). Again, there was a much greater emphasis placed on the support needed to deliver quantitative methods teaching for students to successfully complete their individual research projects than on anything else.

Table 6: Registration data - how can Cardiff University best support the teaching and learning of the Skills Challenge Certificate?

\begin{tabular}{lcc}
$\begin{array}{l}\text { Do you have any other comments for Cardiff University } \\
\text { on how best to support the teaching and learning of } \\
\text { the Skills Challenge Certificate or any other challenges } \\
\text { within the Welsh Baccalaureate? }\end{array}$ & $\begin{array}{c}\text { Frequency } \\
\text { Numeracy }\end{array}$ & $\begin{array}{c}\text { Valid } \\
\text { percentage } \\
\text { (\%) }\end{array}$ \\
Handling data & 2 & 33.3 \\
Creating questionnaires & 1 & 16.7 \\
Enterprise and employability challenge & 1 & 16.7 \\
Evidence of acceptance of WBQ by universities & 1 & 16.7 \\
Masterclasses for students & 1 & 16.7 \\
\hline
\end{tabular}

\section{Evaluation data}

At the end of the conference, delegates completed a short evaluation form. The evaluation data revealed that, on average, delegates believed that all the workshops were relevant. Delegates were asked to score the workshops from 1 ('Not at all relevant') to 5 ('Very relevant'). Table 7 shows that the median scores for all the workshops were above 4, indicating that participants found the workshops to be relevant. The workshops on survey design and developing interview schedules were deemed the most relevant. The relevance of the workshops was underscored in the qualitative comments given in the feedback. For instance, delegates described the conference as 'Coherent, purposeful and engaging' and 'Comprehensive and thorough'. 
Table 7: Evaluation data: Relevance of workshops

\begin{tabular}{lcc}
\hline Workshop & Median score & Descriptor \\
\hline Open access resources & 4 & Relevant \\
School health research network & 4 & Relevant \\
Survey design & 5 & Very relevant \\
Developing interview schedules & 5 & Very relevant \\
Analysing quantitative data & 4 & Relevant \\
Analysing qualitative data & 4 & Relevant \\
Visual methods & 4 & Relevant \\
\hline
\end{tabular}

Looking specifically at the feedback for the workshops aimed at developing numerical skills, the median score for the relevance of the survey design workshop was 5 ('Very relevant'), while the median score for the relevance of the quantitative data analysis workshop was 4 ('Relevant') (see Table 7). The qualitative comments indicated that some participants found these sessions particularly advantageous, and that the sessions had equipped them with the necessary confidence to begin to deliver more quantitative research methods teaching. For instance, when asked about the most successful aspects of the conference, delegates said: 'Quantitative data analysis workshop - because I can use it in class to help improve grades' and 'Quantitative workshops ... interactive and useful for teaching'. However, some delegates found the material too 'complex' and stated that it 'was a bit above [their] head'. One delegate expressed the need for more 'quantitative data help', while another stated that they 'would have liked more time to understand the quantitative data'. This links to some of Estyn's (2018) recent concerns over the variability and skill level of teachers delivering the qualification. It also highlights the skills gap that needs to be addressed to ensure that the qualification fulfils its potential and adequately prepares young people for higher education and the workplace.

This dichotomy of opinions was not as apparent or stark for the qualitative workshops. In contrast, the only concern raised in relation to these workshops was in regard to their acceptance by the WJEC as a legitimate means of researching and obtaining knowledge. For instance, one participant stated: 'It would be useful to check with WJEC if aspects spoken about in conference are acceptable (e.g. visual methods)'. This suggests that anxiety about teaching the individual investigation aspect of the SCC lies predominately in the delivery of quantitative research methods. This poses a challenge for the Cardiff Q-Step Centre and the Welsh education system more broadly, if we are to ensure that future generations are sufficiently trained to analyse and work with big data efficiently and effectively.

\section{Discussion and conclusions}

Cardiff University (2018a, 2018b) states in its strategy document The Way Forward, in relation to its 'civic mission', that 'we will work with colleges, educational partners, and all schools in Wales through our Strategic Framework for School Engagement, supporting teachers and working towards improved educational attainment'. As such, it appears that the initiatives of the Cardiff Q-Step Centre described in this paper align closely with this strategic vision. However, these findings are also of wider relevance beyond Wales, given the similarities to the Extended Project Qualification (EPQ), which 
is now widely offered across both England and Wales. As such, engaging in outreach with teachers of the WBQ and EPQ could be a way in which universities more generally contribute towards their 'civic mission' strategies.

As we discussed in the introduction to this paper, traditional university outreach in schools has predominantly focused on working with school students to develop their skills and knowledge as preparation for higher education or as a means of recruiting future students (Bartel et al., 2003). However, the findings of this paper highlight the need to view outreach in schools as moving beyond simply engaging with school students and to consider the ways in which academic knowledge can also benefit the ongoing development of teachers. As we have shown, the delegates registered for the 2018 Skills Challenge Certificate Conference were not predominantly STEM teachers, and almost half were teaching the WBO in addition to their specialist subjects, which included art, information technology and business studies. We suggested that many of the delegates therefore did not have the research or quantitative skills necessary to confidently teach their students the skills they needed to succeed in the Individual Project. Indeed, difficulties with number were shown to be the biggest area of concern for delegates prior to the event, and we therefore suggest that centres such as the Cardiff Q-Step Centre have a key role to play in supporting teachers to develop these skills.

The findings of this study also indicate that many teachers had attended the Skills Challenge Certificate Conference in 2018 in order to gain teaching ideas and resources that they could use as project ideas for their students. Again, we suggest that this is another area where universities can engage teachers with their research projects. For example, at the 2018 conference, Cardiff University's School Health Research Network (SHRN) delivered a session for teachers about data they collect that are summarized in school-level reports that students could use in their Individual Projects. Other university departments and outside organizations also showcased their research in the form of project briefs that teachers could use or develop for their own students. Thus, we argue that such outreach with teachers also offers academics an alternative method of disseminating their research, which also contributes towards the 'civic mission' of the university.

\section{Next steps: Future outreach plans with teachers of the Welsh Baccalaureate Qualification}

In light of the evidence here, the Cardiff Q-Step Centre along with the consortiums in Wales have decided that the 2019 SCC conference should focus specifically on the development of numeracy for the individual investigation part of the SCC. Specifically, the conference programme has been designed to afford teachers the opportunity to become more familiar with open access data sets and how these can be analysed using Microsoft Excel. This will enable teachers to encourage their students to engage with existing data across a range of diverse topics and to undertake more sophisticated data analysis. One of the anticipated challenges of adopting this focus is the range of abilities among teachers. While some who deliver the Welsh Baccalaureate SCC are qualified STEM teachers (see Table 3) and confident with number, the majority have had no engagement with number for several years, and may have only achieved minimum maths GCSE or the equivalent requirements at the time they qualified. While some of these teachers are keen to develop their skills, others are apprehensive (even scared) to engage with number work. Delivering to a wide spectrum of abilities presents a challenge that the team need to consider carefully. 
It is important for the Cardiff Q-Step Centre, and the higher education system more widely, that these teachers embrace quantitative methods in order to ensure that our future learners are better equipped for post-compulsory study and for learning, working and living in society full of big data. We suggest that it is here where university researchers have a key role to play in continued engagement work with schools. Such engagement could help Cardiff University fulfil its civic mission of engaging with all schools in Wales over the next five years (Cardiff University, 2018a, 2018b). The university's strategic mission underscores the role that the higher education sector has in improving educational standards and attainment. Given that the WBO is exclusive to Wales, and that the National Assembly for Wales (Children, Young People and Education Committee, 2019) has recently reiterated its commitment to the continuation of the qualification in the future, this gives Cardiff University a platform from which it can make a unique and valuable contribution to teaching practice. Indeed, this is further supported by the recent National Assembly for Wales (ibid.) report, which suggests that a focus on future development of the qualification should be on the delivery of the qualification and ensuring that teachers of the qualification receive ongoing training to support its delivery. However, the findings of this paper will also be of relevance more broadly across England and Wales where the Extended Project Qualification is now being offered to students more widely.

\section{Notes on the contributors}

Charlotte Brookfield is a lecturer in social sciences based in the Cardiff Q-Step Centre of Excellence in Quantitative Methods Teaching and Learning. Her role includes responsibility for maintaining and developing links between Q-Step, the further education sector and related external agencies.

Samuel Parker is a lecturer in psychology in the School of Social Sciences at Birmingham City University. In addition to his research on the integration of refugees and asylum seekers, Samuel has also worked with Charlotte on a number of engagement activities related to the teaching of research methods for teachers and students of the Welsh Baccalaureate Qualification.

\section{References}

Bartel, A.S., Krasny, M. and Harrison, E.Z. (2003) 'Beyond the binary: Approaches to integrating university outreach with research and teaching'. Journal of Higher Education Outreach and Engagement, 8 (2), 89-104.

British Academy (2012) Society Counts: Quantitative studies in the social sciences and humanities. London: British Academy. Online. https://tinyurl.com/y65olk72 (accessed 2 November 2019).

Cardiff University (2018a) The Way Forward 2018-2023. Cardiff: Cardiff University. Online. https://tinyurl.com/y2pvmnkq (accessed 2 November 2019).

Cardiff University (2018b) The Way Forward 2018-2023: Civic mission sub-strategy. Cardiff: Cardiff University. Online. https://tinyurl.com/yypenczo (accessed 2 November 2019).

Children, Young People and Education Committee (2019) Bacc to the Future: The status of the Welsh Baccalaureate qualification. Cardiff: National Assembly for Wales.

Crawford, S.D., Couper, M.P. and Lamias, M.J. (2001) 'Web surveys: Perceptions of burden'. Social Science Computer Review, 19 (2), 146-62.

Estyn (2018) New Qualifications. Cardiff: Estyn. Online. https://tinyurl.com/y3n3rood (accessed 2 November 2019).

Golding, S.M. (2013) 'Raising Pupils' Educational and Occupational Aspirations'. Unpublished EdD thesis, Cardiff University. 
Greatbatch, D., Wilmut, J. and Bellin, W. (2006) External Evaluation of the Welsh Baccalaureate Qualification Pilot. Cardiff: Welsh Assembly Government. Online. https://tinyurl.com/ybgdaahd (accessed 2 November 2019).

Grigg, R. (2016) '“Leave me alone and let me teach": Teachers' views of Welsh Government education policies and education in Wales'. Wales Journal of Education, 18 (1), 64-86.

Gunning, D. and Raffe, D. (2011) '14-19 education across Great Britain - convergence or divergence?'. London Review of Education, 9 (2), 245-57.

Johnson, M., Danvers, E., Hinton-Smith, T., Atkinson, K., Bowden, G., Foster, J., Garner, K., Garrud, P., Greaves, S., Harris, P., Hejmadi, M., Hill, D., Hughes, G., Jackson, L., O’Sullivan, A., Ó Tuama, S., Perez Brown, P., Philipson, P., Ravenscroft, S., Rhys, M., Ritchie, T., Talbot, J., Walker, D., Watson, J., Williams, M. and Williams, S. (2019) 'Higher education outreach: Examining key challenges for academics'. British Journal of Educational Studies, 1-23. Online. https://tinyurl.com/y4wey48m (accessed 4 November 2019).

Michels, B.I. and Eijkelhof, H.M.C. (2018) 'High-school students engaging with researchers within a pre-university programme: Motivations and experiences'. Research for All, 2 (1), 43-61.

National Assembly for Wales Research Service (2015) The Welsh Baccalaureate Qualification: Quick guide. Cardiff: National Assembly for Wales. Online. https://tinyurl.com/y63sbmzt (accessed 4 November 2019).

Nuffield Foundation (n.d.) Programme Background: Promoting a step-change in the quantitative skills of social science undergraduates. London: Nuffield Foundation. Online. https://tinyurl.com/y6y2opo3 (accessed 4 November 2019).

Qualifications Wales (2016) Review of the Implementation of the New Welsh Baccalaureate from September 2015. Newport: Qualifications Wales. Online. https://tinyurl.com/y263dv8m (accessed 4 November 2019).

Savage, M. (2009) 'Contemporary sociology and the challenge of descriptive assemblage'. European Journal of Social Theory, 12 (1), 155-74.

Savage, M. and Burrows, R. (2007) 'The coming crisis of empirical sociology'. Sociology, 41 (5), 885-99.

Savage, M. and Burrows, R. (2009) 'Some further reflections on the coming crisis of empirical sociology'. Sociology, 43 (4), 762-72.

Shaw, A.J., Harrison, T.G. and Shallcross, D.E. (2010) 'What value has chemistry outreach by a university department to secondary schools? Teacher perceptions of Bristol ChemLabS outreach events'. Acta Didactica Napocensia, 3 (3), 15-23.

Tansey, L. and Gallo, M. (2018) 'From homework club to social justice: Critical reflections on student volunteering through the examination of a school-university partnership'. Research for All, 2 (1), 76-92.

Universities UK (2015) Making the Most of Data: Data skills training in English universities. London: Universities UK. Online. https://tinyurl.com/y43gkqc4 (accessed 4 November 2019).

Welsh Government (2012) Review of Qualifications for 14 to 19-year-olds in Wales. Caerphilly: Welsh Government.

Welsh Government (2018) The Welsh Language Standards (No. 7) 2018. Online. www.legislation.gov.uk/wsi/2018/441/made (accessed 27 November 2019).

WJEC (Welsh Joint Education Committee) (2019) 'Welsh Baccalaureate'. Online. https://tinyurl.com/y5fzj97c (accessed 4 November 2019).

Yhnell, E., Wood, H., Baker, M., Amici-Dargan, S., Taylor, C., Randerson, P. and Shore, A. (2016) 'The impact of attaining the Welsh Baccalaureate Advanced Diploma on academic performance in bioscience higher education'. International Journal of Science Education, 38 (1), 156-69. 